\title{
High level of resistance in the mosquito Anopheles arabiensis to pyrethroid insecticides from low malaria transmission zone of Moroto district, Karamoja region, Uganda: Implication for malaria vector control
}

Richard Echodu ( $\square$ richardechodu2009@gmail.com )

Gulu University Bioscience Research Laboratories

Juliet Anena

Gulu University

Tereza Iwiru

Gulu University

Paul Mireji

Kenya Agricultural and Livestock Research Organization

Geoffrey Maxwell Malinga

Gulu University Faculty of Science

Elizabeth A. Opiyo

Gulu University Faculty of Science

Julius Iga

Gulu University Faculty of Science

Onanyang David

Gulu University Faculty of Science

\section{Research}

Keywords: Insecticide resistance, deltamethrin, permethrin, pirimiphos-methyl, low malaria transmission zone, Moroto, Karamoja, Uganda

Posted Date: March 11th, 2020

DOI: https://doi.org/10.21203/rs.3.rs-16734/v1

License: (9) (1) This work is licensed under a Creative Commons Attribution 4.0 International License. Read Full License 


\section{Abstract}

Background Karamoja region of Uganda previously classified as low malaria transmission zone is currently experiencing significant upsurge of malaria incidences. Long lasting insecticidal nets (LLINs) impregnated with pyrethroids constitute a major tool for malaria control in this region. Efficacy of this tool can be hampered by resistance to the pyrethroids in the Anopheles mosquito vectors. Resistance status of these mosquitoes in this region is poorly understood, effectively hampering better understanding of the impact of LLINs in the malaria control initiative. Here, we assessed susceptibility of the Anopheles arabiensis from the region to deltamethrin, permethrin (pyrethroids) and pirirmiphos-methyl (organophosphate) insecticides. Method We collected anopheline mosquito larvae from their natural habitats and reared them to adult emergence in situ field insectary in Karamoja region. We then identified them morphological to species level and exposed 513 emerge adult female An gambiae s.l., mosquitoes to diagnostic dosages of deltamethrin (0.05\%), permethrin $(0.75 \%)$ and pirimiphos-methyl $(0.25 \%)$ pyrethroids exposure using the standard WHO insecticide susceptibility test assay. Synergic assays using piperonyl butoxide (PBO) were done to check for the involvement of detoxification enzymes in pyrethroid resistant populations. We then screened for knockdown resistance (KDR) and mosquito species diversity using Polymerase Chain Reaction (PCR). Results Majority (96\%) of the mosquitoes we sampled were identified as An. arabiensis and $4 \%$ as An. gambiae sensu stricto . We observed cross-resistance to both deltamethrin (11.9\%) and permethrin (47\%) but susceptibility (100\% mortality) to pirimiphos-methyl in An. arabiensis. The pre-exposure to PBO ameliorated the resistance to both pyrethroids. We detected homozygous KDR -eastern variant in 1.8 and $50 \%$ of the An. arabiensis and An. gambiae s.s. respectively. Conclusion Anopheles arabiensis and An. gambiae s.s. are the malaria vector in Karamoja region with An. arabiensis predominating. Both species are susceptible to pirimiphos-methyl but resistant to both deltamethrin and permethrin, through a metabolic process (phenotype). Mosquotoes with genetic (kdr) mutations for resistance were minimal and hence have minimal contribution to the pyrethroid resistance profile. An. arabiensis can thus be controled in Karamoja region using deltamethrin and/or permethrin impregnated mosquito nets integrated with PBO and/or through indoor residual spraying of sprayable human dwellings with pirimiphos-methyl.

\section{Background}

Malaria is a leading cause of morbidity and mortality in the tropics despite reduction in global malaria burden [1, 2] The decline has been attributed to use of long-lasting insecticidal nets (LLINs), indoor residual spraying (IRS), introduction of artemisin-based combination therapy (ACT) for malaria treatment and intermittent preventive treatment (IPTp) during pregnancy [2]. Despite these significant gains, long-term effectiveness of malaria vector controls using LLINs and IRS is currently being challenged by widespread insecticide resistance in mosquito populations $[3,4]$.

World Health Organization (WHO) recommends expansion of insecticide resistance monitoring and surveillance within national and regional control programs [5]. This initiative can 1) provide insights into mechanisms that can drive resistance, 2) characterize effectiveness of control efforts and 3) identify causes of any failures within the controlled areas for effective implementation and sustainable vector control [6, 7] WHO recommend organochlorines, organophosphates, pyrethroids and carbamates for control of malaria vectors, among which pyrethroids are the only WHO prequalified insecticides for LLINs, and are also extensively used for IRS due to their low cost, human safety and long duration of residual action [5]. The LLINs and IRS are widely promoted 
and implemented as public health intervention tool for malaria control in most malaria-endemic countries including Uganda [8]. The LLINs is selectively implemented in the different regions, with an average operational coverage of over $95 \%$ [9]. The control programmes are concentrated in high/medium transmission zones while low malaria transmission zones, including Karamoja region have largely been neglected [10, 11]. Despite extensive LLINs implementation, over the recent years Karamoja experienced significant (>60\%) malaria incidences between 2015 to 2017 [9, 12] with Moroto district registering 334.5 cases per 1000 children under 5 years [13]. This translates into about $33 \%$ disease prevalence and may be linked to factors such as pyrethroid resistance that might be impeding efficacy of the LLINs

Pyrethroids exert their insecticidal effect on the voltage-gated sodium channel (VGSC) located on the membrane of neurons [14]. When pyrethroids bind an open channel, they block its closure, thus extending the action potential and resulting in the insect's rapid paralysis, a phenomenon known as "knockdown" (kdr) [15]. However, mosquito resistance to pyrethroids is an emerging challenge to efficacy of otherwise successful insecticidetreated nets (ITN) based malaria control intervention against adult vector [16]. This is particularly of great concern to sub-Saharan Africa, with high malaria transmission levels and major vectors (An. funestus, An. gambiae s.s. and An. arabiensis) resistant to pyrethroids (Mnzava et al., 2015) [17]. The resistance is mediated through knockdown resistance ( $\mathrm{kdr}$ ) mutations, enhanced detoxification of pyrethroids by the mosquito enzymes (esterases, monooxygenases and glutathione $S$-transferases $[3,18]$ and probably other unknown mechanisms such as behavioral and penetration $[19,20]$ known to occur in other vectors $[21,22]$.

This present study was initiated to establish distribution of major malaria vectors and their resistance status to deltamethrin, permethrin (pyrethroids) and pirirmiphos-methyl (organophosphate) insecticides in Karamoja region of Uganda. Our findings, reported herein, will contribute to designing suitable control interventions and improve implementation of resistance management strategies across Karamoja region of Uganda.

\section{Methods}

\section{Study area}

Karamoja lies between $1^{\circ} 30^{\prime}$ to $4^{\circ} 06^{\prime} \mathrm{N}$ and $33^{\circ} 30^{\prime}$ to $35^{\circ}$ covering an area of $29,430 \mathrm{~km}^{2}$ forming the northeastern part of Uganda with a human population of about 1.1 million [23]. This region encompasses Abim, Amudat, Kaabong, Karenga, Kotido, Moroto, Nabilatuk, Napak and Nakapiripit districts. The region has 53.8 to 63.5\% Human Poverty Indices (HPI) compared to $37.5 \%$ Uganda national average [24]. Most of the population are nomadic pastoralist. The region is characterized by savannah woodlands and semi-desert vegetation with 1200 and $1500 \mathrm{~m}$ plateaus and Kadam, Akisim and Napak Mountains and Moroto mountain (about 3083m above sea level) [25]. The region is drained by Turkwel River, part of internal drainage basin of Lake Turkana in Kenya. Karamoja experiences only one rain season which occurs from May to July. The mean annual rainfall level is between 350 and $750 \mathrm{~mm}$ [26]. Ambient temperatures range from $16^{\circ} \mathrm{C}$ to $30^{\circ} \mathrm{C}$. The species of Anopheles mosquitoes in the and Anopheles gambiae sensu stricto Giles 1902 [27]. Malaria transmission in the region is absolutely (100\%) attributed to Plasmodium falciparum parasite [28]. Malaria prevalence in the region has increased by 30\% with average incidence ranging from 166 in 2015 to 295 in 2018 per 1000 people [9]. The LLINs which is the only malaria vector control strategy employed in the region with $57 \%$ households owning more than one ITN with ratio of use and access of $0.95[11,29]$ This indicate low ratio of people sleeping inside nets. 


\section{Mosquito collections}

We collected mosquito larvae stages 3,4 and pupae from their aquatic breeding habitats in Moroto $\left(\mathrm{NO2}^{\circ} 32.0^{\prime}\right.$ E34 $\left.40.0^{\prime}\right)$ in the rainy month of July 2019 using dipping technique. The sites included brick pits, puddles, road side drains and excavations, sand pits and open gardens. Immediately after sampling, the larvae were transferred to a field insectary where they were maintained at a density of 500 larvae per three liters in their natural water that contained dissolved natural foods. We kept the emergent adult mosquitoes in standard $30 \times 30 \times 30 \mathrm{~cm}$ cages in under the ambient insectary environmental conditions. We identified An. gambiae s. I among emerged mosquito adults using morphological keys [30]offered them $10 \%$ glucose solution ad libitum and tested the females for insecticide resistance 2-5 days post emergence. We obtained ethical clearance for mosquito collection from Uganda National Council for Science and Technology (authorization No SS 4610).

\section{Insecticide susceptibility bioassay}

We conducted insecticide susceptibility tests on 2-5 days old non-fed adult female An. gambiae s.I. mosquitoes using the standard WHO tube bioassay protocol for assessing potential insecticide resistance [31] at Gulu University mosquitoes insectary. To simulate natural conditions, we maintained an average temperature in the insectary at $29 \pm 2^{\circ} \mathrm{C}$ (day) and $24 \pm 2^{\circ} \mathrm{C}$ (night), with relative humidity (RH) ranging from 57 to 70 and a photoperiod of $12: 12 \mathrm{~h}(\mathrm{~L}-\mathrm{D})$. Our overall maintenance of the colony followed standard operating procedure for rearing Anopheles mosquitoes [32]. We exposed 492 female An. arabiensis to $0.05 \%$ deltamethrin, $0.75 \%$ permethrin or $0.25 \%$ pirimiphos-methyl concentrations on insecticide-impregnated papers or control (oil-treated) (Vector Control Research Unit, Universiti Sains Malaysia) for 60 minutes. During this exposure duration, we recorded the number of mosquitoes knocked-down at 10, 15, 20, 30, 40, 50 and 60 minutes intervals post exposure. After the exposure period, mosquitoes were transferred to holding tubes and maintained on $10 \%$ glucose solution. The final mortalities were determined after $24 \mathrm{~h}$ post exposure. After the bioassays, we collected dead (susceptible) and alive (resistant) mosquitoes, and stored them individually in separate Eppendorf tubes with silica gel for subsequent molecular laboratory analysis.

\section{Evaluation of potential impact metabolism on resistance to the pyrethroids in the mosquitoes}

To evaluate if metabolism of the pyrethroids by the mosquitoes was responsible for the insecticide resistance we observed, we assessed relative mortality of the mosquitoes exposed to the pyrethroids with or without piperonyl butoxide (PBO) that prevents pyrethroid catabolism by Cytochrome P450 oxidase that can detoxify the active ingredient before an insecticidal effect can occur [33]. This inhibition produces a synergistic effect [34]. Briefly, we assessed this effect using WHO protocol [31] where we pre-exposed adult female An. gambiae s.I to WHO papers impregnated with 4\% PBO an oxidase inhibitor for 1 hour. This was followed immediately with exposure to discriminating doses of $0.05 \%$ deltamethrin and $0.75 \%$ permethrin on impregnated papers for 60 minutes. Five replicated were performed for each exposure set. We recorded the knock-down rates at 10, 15, 20, 30, 40, 50- and 60-minutes intervals during the one-hour exposure to synergist and to insecticides (deltamethrin or permethrin). We immediately assessed the resultant mortality of the flies from the three treatments (PBO + deltamethrin or permethrin exposed or unexposed mosquitoes). The live mosquitoes were fed on $10 \%$ glucose solution. Mortality rates from assays conducted with and without exposure to PBO (synergist) were scored after 24 hours of exposure. Mortality rates were compared between PBO deltamethrin or permethrin exposed and unexposed mosquitoes. Resistance was also compared with pirimiphos-methyl to ascertain which test 
mosquitoes were fully susceptible. All mosquitoes tested were identified to species level by PCR as described in mosquitoes species identification subsection below.

\section{PCR identification of memebers of An. gambiae s.I. and An. funestus s.l.}

We identified our mosquitoes (post exposure) to their An. gambiae s./ sibling species status using PCR methods of [35], and for members of the An. funestus s.l. group using a method of Koekemoer et al., [36]. We extracted total genomic DNA (gDNA) from whole flies using the DNeasy blood and tissue kits (Qiagen, Valencia, CA) following the manufacturer's protocols and assessed the quality of the DNA on $1.5 \%$ agarose gel as visualized on Gel Doc Imaging System (UVITEC, Cambridge). Our primers included those specific to An. gambiae s.s, An. arabiensis as well as the universal An. gambiae s.l. complex primer [35]. Similarly, specific primers for $A n$. funestus s.s. and universal primer for the An. funestus group were also used for the An. funestus s.I. [36]. In the PCR reaction, we amplified 2.5 $\mathrm{l}$ gDNA with 1 unit of GoTaq Green Master Mix (Promega, Madison, MO) in the buffer in a total volume $12.5 \mu \mathrm{l}$. For An. funestus complex, conditions remained the same except that we added $0.5 \mathrm{mM}$ of $\mathrm{MgCl}_{2}$. We run the reactions in touch screen thermal cycler (SimpliAmp, Applied Biosystems, Life Technologies, Singapore). The first cycle included five minutes at $95^{\circ} \mathrm{C}, 30$ seconds at $50^{\circ} \mathrm{C}$, and 30 seconds at $72^{\circ} \mathrm{C}$. Subsequent cycles involved 1 minute at $94^{\circ} \mathrm{C}, 30$ seconds at $50^{\circ} \mathrm{C}$, and 1 minute at $72{ }^{\circ} \mathrm{C}$ for 30 cycles. We also run positive and no-sample negative controls. We loaded The PCR products onto 1X SYBR safe (Invitrogen, 5791 Allen Way Carlsbad CA 92008, USA) 2 \% agarose gels (AppliChem GmbH Ottoweg Damstadt Germany) in a TBE (40mM Tris-HCl pH 8.3, $45 \mathrm{mM}$ boric acid, and 1mM EDTA) buffer and run a 100 bp DNA ladder molecular weight marker (Life Technologies, Rockville, MD) to confirm expected molecular weights of the amplification products. We documented our PCR products using GelDoc Imaging System (UVITEC, Cambridge).

\section{Detection of East African kdr resistance mutations in An. gambiae s.l.}

We also used the methods described by Ranson et al., [37] to detect single base pair specific single nucleotide polymorphisms (SNPs) leucine to serine substition TTA/TCA mutation in the voltage-gated sodium channel known as knockdown resistance to DDT and pyrethroids in East Africa. Briefly, we amplified $5 \mu$ gDNA, $0.2 \mu \mathrm{M}$ of the specific primers (AgD1, AgD2, AgD4 and AgD5) with 1 unit of GoTaq Green Master Mix (Promega, Madison, MO) in the buffer in a total volume $25 \mu$ l. We run the reactions in touch screen thermal cycler (SimpliAmp, Applied Biosystems, Life Technologies, Singapore). We used touch down PCR conditions with the initial denaturation at $95^{\circ} \mathrm{C}$ for 5 minutes followed by 10 cycles of denaturation at $94^{\circ} \mathrm{C}$ for 1 minute, annealing at $54^{\circ} \mathrm{C}$ for 30 seconds and extension of $72^{\circ} \mathrm{C}$ for 30 seconds. This was followed by 30 cycles of denaturation at $94^{\circ} \mathrm{C}$ for 1 minute, annealing at $47^{\circ} \mathrm{C}$ for 30 seconds and extension at $72^{\circ} \mathrm{C}$ for 30 seconds with the final extension of $72^{\circ} \mathrm{C}$ for 10 minutes and holding at $4^{\circ} \mathrm{C}$ until when collected. We also run positive and no-sample negative controls. PCR products analysis was carried out as described in mosquito species identification subsection above.

\section{Data analysis}

We corrected the knockdown rates for testing the toxicity of each insecticide by Abbott's formula [38] and then transformed them to Probits [38] for linear regression analysis and the determination of $50 \%$ knockdown $\left(\mathrm{KD}_{\mathrm{t} 50}\right)$. For Probit analysis, we used GraphPad Prism version 7.00 for Mac (GraphPad Software, La Jolla California USA). We used weighted mean summarize knockdown due to different insecticides, and adopted 
WHO criteria of interpretation of our results. Consequently, we considered mosquito population to be 1) resistant (confirmed) to a particular insecticide if mortality rate was $0-79 \%, 2$ ) resistant suspected if mortality was $80-97 \%$ and more investigations are required, and 3) susceptible when the mortality was $98-100 \%$.

Data for the metabolic tests were summarized as mean percent mortality of the five replicates, and the $95 \%$ confidence intervals were calculated. The final mortality observed 24-hour post-exposure was compared between samples with and without pre-exposure to PBO, using paired sample t-test. Pearson's chi-square was used to evaluate the association of kdr frequency with WHO assay results. All statistical analyses were performed in SPSS v25 with level of significance set at $a=0.05$.

\section{Results}

\section{Susceptibility of $A n$. arabiensis to pyrethroids}

Results of bioassay of adult female An. gambiae s.I. ( $\mathrm{N}=513)$ for susceptibility to the three insecticides are summarized in Figure 1 and Table 1. Based on WHO criteria, [31], resistance (<95\% mortality) of An. arabiensis to deltamethrin and permethrin was observed in all the samples, with mortality varying from $12 \%$ to $91 \%$ in Moroto (Table 2). Susceptibility of An. arabiensis to pirimiphos-methyl was observed in Moroto (Table 2).

\section{Impact of PBO on toxicity permethrin and deltamethrin to An. arabiensis}

An hour pre-exposure of An. arabiensis to PBO enhanced toxicity of deltamethrin (from 11.8 to $90 \%$ ) or permethrin (from 47 to 89.2\%) in Moroto, compared to cohorts directly exposed to each of the two candidate insecticides without PBO pre-exposure (Figure 1), suggesting potential cytochrome P450 oxidase mediated resistance [39] to these insecticides in the mosquito. However, our observations that the pre-exposure to PBO partially abolished resistance to deltamethrin and permethrin in Moroto still suggests partial role of the cytochrome P450 oxidase in the resistance phenotype while other mechanisms might also play a role (Figure 1 and Table 2).

In the absence of PBO, the $\mathrm{LT}_{50}$ for deltamethrin and permethrin on An. arabiensis were similar (Table 3 and Figure 3). However, the PBO significantly reduced the $\mathrm{LT}_{50}$ for both deltamethrin and permethrin on $A n$. arabiensis relative to their respective native formulations (without PBO). Additionally, incorporation of PBO reduced the $\mathrm{LT}_{50}$ in permethrin more than it did with deltamethrin (Table 3).

\section{An. gambiae s.l. species identification}

Our subsequent PCR of sibling species on most of the mosquitoes $(\mathrm{N}=342)$ post exposure revealed that most of the mosquitoes were An. arabiensis (96\%) with the rest being An. gambiae s.s. (4\%). No An. funestus species was detected.

\section{Table 1: Knockdown summary during 60 minutes exposure}




\begin{tabular}{|l|l|l|l|l|l|l|l|l|l|l|}
\hline \multirow{2}{*}{$\begin{array}{l}\text { Insecticide } \\
\text { Tested }\end{array}$} & \multicolumn{6}{|c|}{ No. of Knocked down Mosquitoes } & Total Exposed & $\begin{array}{l}\text { KT50 } \\
\text { (min) }\end{array}$ & $\begin{array}{l}\text { KD60 } \\
\text { (\%) }\end{array}$ \\
\cline { 2 - 10 } & 10 & 15 & 20 & 30 & 40 & 50 & 60 & & 60 & 51 \\
\hline Pirimiphos-methyl & 0 & 1 & 3 & 9 & 15 & 30 & 56 & 110 & 40 & 83 \\
\hline Deltamethrin & 1 & 3 & 11 & 25 & 51 & 79 & 84 & 101 & 15 & 100 \\
\hline Deltamethrin PBO & 23 & 63 & 76 & 90 & 96 & 100 & 100 & 100 & 40 & 95 \\
\hline Permethrin & 2 & 12 & 18 & 45 & 65 & 89 & 95 & 100 & 15 & 99 \\
\hline Permethrin PBO & 34 & 86 & 94 & 95 & 98 & 100 & 101 & 102 & & \\
\hline
\end{tabular}

*KT50: Time after which 50\% of the Anopheles tested are knocked down.

*KD60: Proportion of Anopheles knocked down after 60 minutes.

Table 2: Mean percentage mortalities following exposure of 2-5 day old An. arabiensis to pirirmiphos-methyl, deltamethrin and permethrin. Mortalities were recorded 24 hours post exposure (for 60-minutes)

\begin{tabular}{|c|c|c|c|c|c|c|}
\hline \multirow{2}{*}{$\begin{array}{l}\text { Insecticide } \\
\text { tested }\end{array}$} & \multicolumn{3}{|l|}{ EXPOSED } & \multicolumn{3}{|c|}{ CONTROL } \\
\hline & Mortality & $\begin{array}{l}\text { Total } \\
\text { Exposed }\end{array}$ & $\begin{array}{l}\% \text { Mortality in } \\
\text { exposed }\end{array}$ & Mortality & $\begin{array}{l}\text { Total } \\
\text { Exposed }\end{array}$ & $\begin{array}{l}\text { \% Mortality in } \\
\text { control }\end{array}$ \\
\hline $\begin{array}{l}\text { Pirimiphos- } \\
\text { methyl }\end{array}$ & 110 & 110 & 100 & 00 & 55 & 00 \\
\hline Deltamethrin & 12 & 101 & 12 & 00 & 49 & 00 \\
\hline $\begin{array}{l}\text { Deltamethrin } \\
\text { PBO }\end{array}$ & 90 & 100 & 90 & 00 & 50 & 00 \\
\hline Permethrin & 47 & 100 & 47 & 00 & 50 & 00 \\
\hline $\begin{array}{l}\text { Permethrin } \\
\text { PBO }\end{array}$ & 93 & 102 & 91 & 00 & 50 & 00 \\
\hline
\end{tabular}

Table 3: Median Lethal Time for knockdown in Adult female An. arabiensis mosquitoes (from Moroto district, Uganda) by various formulations of pyrethroids. 


\begin{tabular}{cccccc}
\hline Pyrethroid & PBO & LT $_{\text {50, Min }}$ & 95\% CI & Slope $(\boldsymbol{\beta} \pm \mathrm{SE})$ & $\boldsymbol{\chi}^{\mathbf{2}}$ \\
\hline Deltamethrin & - & 39.13 & $34.03-70.73$ & $4.18 \pm 0.90$ & 3.532 \\
& + & 13.44 & $11.95-15.24$ & $3.43 \pm 0.46$ & 3.646 \\
\multirow{3}{*}{ Permethrin } & - & 37.02 & $30.69-63.59$ & $2.73 \pm 0.43$ & 2.973 \\
& + & 11.03 & $10.47-11.67$ & $6.09 \pm 0.62$ & 2.377 \\
\hline
\end{tabular}

PBO - Piperonyl Butoxide, (+) - with PBO, (-) - Without PBO, CI- Confidence Interval, LT - Median lethal Time.

We have summarized our distribution of L1014S mutations from genotyping of An. arabiensis ( $\mathrm{n}=328)$ and $A n$. gambiae s.s. (15) in Table 4. Of the 328 An. arabiensis tested for kdr east allele, 66.2\% ( $n=217)$ were homozygous for wild type alleles (SS) and $1.2 \%(n=4)$ were homozygous for mutation alleles (RR). Of the $15 \mathrm{An}$. gambiaes.s, 33.3\% $(n=5)$ were homozygous for the susceptible wild type (SS), $13.3 \%(n=2)$ were homozygote mutation alleles (L1014S) and only $6.7 \%(n=1)$ was heterozygous (HR).

Table 4: KDR allele frequencies

\begin{tabular}{|c|c|c|c|c|c|c|}
\hline $\begin{array}{l}\text { Mosquitoes } \\
\text { species }\end{array}$ & Insecticide & $\begin{array}{l}\text { Survival } \\
\text { status } \\
\text { after } \\
\text { exposure }\end{array}$ & $\begin{array}{l}\text { \# } \\
\text { mosquitoes } \\
\text { tested }\end{array}$ & $\begin{array}{l}\text { Homozygote } \\
\text { mutation } \\
\text { (RR) }\end{array}$ & $\begin{array}{l}\text { Heterozygote } \\
\text { mutation } \\
\text { (RS) }\end{array}$ & $\begin{array}{l}\text { Homozygote } \\
\text { wild type } \\
\text { (SS) }\end{array}$ \\
\hline An. & $\begin{array}{l}\text { Deltamethrin } \\
+ \text { PBO } \\
\text { Exposed }\end{array}$ & Dead & . & 1 & 0 & 39 \\
\hline $\begin{array}{l}\text { An. } \\
\text { gambiae } \\
\text { S.S. }\end{array}$ & $\begin{array}{l}\text { Deltamethrin } \\
+ \text { PBO } \\
\text { Exposed }\end{array}$ & Dead & 4 & 0 & 0 & 3 \\
\hline $\begin{array}{l}\text { An. } \\
\text { arabiensis }\end{array}$ & Deltamethrin & Live & 81 & 1 & 0 & 76 \\
\hline $\begin{array}{l}\text { An. } \\
\text { gambiae } \\
\text { S.s. }\end{array}$ & Deltamethrin & Live & 2 & 1 & 0 & 0 \\
\hline $\begin{array}{l}\text { An. } \\
\text { arabiensis }\end{array}$ & $\begin{array}{l}\text { Permethrine } \\
+ \text { PBO } \\
\text { Exposed }\end{array}$ & Dead & 110 & 0 & 0 & 80 \\
\hline $\begin{array}{l}\text { An. } \\
\text { gambiae } \\
\text { S.S. }\end{array}$ & $\begin{array}{l}\text { Permethrine } \\
+ \text { PBO } \\
\text { Exposed }\end{array}$ & Dead & 3 & 0 & 1 & 2 \\
\hline $\begin{array}{l}\text { An. } \\
\text { arabiensis }\end{array}$ & Permethrin & Live & 40 & & & \\
\hline $\begin{array}{l}\text { An. } \\
\text { gambiae } \\
\text { S.S. }\end{array}$ & Permethrin & Live & 1 & & & \\
\hline $\begin{array}{l}\text { An. } \\
\text { arabiensis }\end{array}$ & $\begin{array}{l}\text { Primiphos } \\
\text { methyl }\end{array}$ & Dead & 42 & 2 & 0 & 22 \\
\hline $\begin{array}{l}\text { An. } \\
\text { gambiae } \\
\text { S.S }\end{array}$ & $\begin{array}{l}\text { Primiphos } \\
\text { methyl }\end{array}$ & Dead & 4 & 1 & 0 & 0 \\
\hline $\begin{array}{l}\text { An. } \\
\text { arabiensis }\end{array}$ & $\begin{array}{l}\text { Primiphos } \\
\text { methyl }\end{array}$ & Live & 0 & 0 & 0 & 0 \\
\hline $\begin{array}{l}\text { An. } \\
\text { gambiae } \\
\text { S.s }\end{array}$ & $\begin{array}{l}\text { Primiphos } \\
\text { methyl }\end{array}$ & Live & 0 & 0 & 0 & 0 \\
\hline
\end{tabular}


KDR - knockdown resistance, PBO - Piperonyl Butoxide, \# - number

\section{Discussions}

We report the first results of resistance in An. arabiensis against pyrethroid in Karamoja region. We established An. arabiensis as the major major malaria vector in Karamoja areas followed by An. gambiae s.s. These two vectors have different genetics and behavior that can have important implications for the epidemiology of malaria and their control. The current use of LLIN in Karamoja region for malaria vector control might be less effective against $A n$. arabiensis. This is mainly due to resistance of the mosquito to the insecticides (deltamethrin and permethrin), more exophagic, exophilic and zoophilic nature of An. arabiensis.

An. arabiensis is being less killed by they two insecticides deltamethrin and permethrin commonly used for the treatment of LLIN. Similar studies have been reported in Kenya and Tanzania [40,41] This happens as a result of the more exophagic, exophilic and zoophilic tendencies of An. arabiensis compared to An. gambiae s.s. behaviors. The exophagic and exophilic nature of An. arabiensis similarly can affect the performance of IRS since these mosquitoes tend to rest and feed outdoors.

In terms of malaria epidemiology, because of the exophagic and exophilic nature of An. arabiensis, this increases the outdoor biting and resting of these mosquitoes leading to high malaria transmission in the area which concedes with what is currently seen in Karamoja region. Besides, An. arabiensis, bite early evening or morning when the population is not protected by LLIN potentially sustaining residual malaria in area with high coverage of net $[42,43]$ Additionally communities in Karamoja region thrive on pastoralism looking for pasture and water for their livestock which pre-expose them to outdoors activities when keeping the livestock and increasing the chances of more outdoor mosquitoes' bites and thus more malaria in the area.

At present, we confirm existence of both mechanisms of insecticide resistances: knock down resistance (kdr) and metabolic resistance due to elevated levels of detoxifying enzymes in the An. arabiensis in Karamoja region. Future planned roll out of LLINs enhanced with PBO might not be a magic bullet since more than one resistance mechanisms were observed in An. gambiae s.I. in Karamonja region.

While the two pyrethroids seems to be having similar performance, PBO significantly enhances the performance of both deltamethrin and permethrin and further enhances that of permethrin over that of deltamethrin (Table 3 ). This suggests that permethrin incorporated with PBO would have a much better performance in addressing the issues of pyrethroids resistance in Moroto than deltamethrin.

These insecticide resistances could as well have important implications for the epidemiology of malaria as well as malaria vector control in the low malaria transmission zones of Karamoja areas. Pyrethroids are the only class of insecticides used in LLINs currently recommended by the World Health Organization. Pyrethroid resistance of malaria vectors is widespread in Africa as well as other classes of insecticides [3, 31, 44] Increased resistance has been attributed to selection pressure from the scale-up of LLINs and IRS [3] and use of similar classes of insecticides in agriculture [45], although the relative contribution of these mechanisms varies by area [46].

Given that resistance has been reported in An. gambiaes.s and An. funestus [47- 50] that are the major malaria vector in Uganda and now An. arabiensis in this current study in Karamoja region, this is a major threat to LLINs 
and IRS use in malaria vector control programmes in the country and the whole of the neighbouring countries. This appears to reflect the need to monitor malaria vector resistance.

Current WHO guidelines recommend combining ITNs and IRS in various transmission settings, especially in areas with holoendemic and epidemic malaria [6]. LLINs and IRS could be employed together in the same households in Karamoja region. Besides, insecticide resistance management should rely on tactical deployment of the active ingredients used for IRS and on LLINs in rotation, combinations (particularly LLINs), mosaics and mixtures as recommended in other studies [6]. What we observed would be important is, if LLINs are to be combined with IRS for malaria prevention and control, the selection of appropriate LLIN types and design should put in consideration the housing structures and cultural issues concerning in-house sleeping patterns and IRS chemicals should be done with caution to avoid further exacerbating existing resistance.

\section{Implication for future malaria vector control}

Nevertheless, the increasing intensity of resistance currently seen in An. arabiensis mosquito populations in Karamoja region will reduce the efficacy of pyrethroid-based interventions. The right course of action for malaria vector control program is therefore to adopt a proactive approach and modify current practices so as to delay the spread of resistance and preserve the effectiveness of deltamethrin and permethrin insecticides.

The high frequencies or intensities of resistance can lead to failure of IRS and can thereby have an epidemiologically significant effect on malaria incidence [51]. There is also cross-resistance between different classes of insecticides that share the same mode of action. The existence of cross- resistance and multiple resistance restricts the choice of alternative insecticides in situations where resistance has been detected. Besides, the impact of the observed spread of resistance will have effectiveness of current vector-control programmes. Therefore, a key element of effective resistance management is the use of alternations, rotations, or sequences of different insecticide mode of action classes. Besides other studies have shown that even in the presence of pyrethroid resistance, insecticide- treated mosquito nets (ITNs) perform better than untreated nets in terms of protection against blood-feeding, and ITNs can induce significant mosquito mortality [4].

We also recommend the use of Larval Source Management (LSM) in order to prevent the completion of development of the immature stages. Mosquitoes breeding sites in Karamoja region can easily be mapped out during the dry season. LSM can be done through 1) Larviciding; the regular application of biological or chemical insecticides to water bodies and 2) biological control: the introduction of natural predators into water bodies.

\section{Limitations}

We acknowledge the limitations of the current study including:

- The time constraints of conducting this research during.

- The sites sampled were predominantly suited for gambiae s.l breeding, thus findings don't rule out possibility existence of $A n$. funestus s.l in the area.

\section{List Of Abbreviations}

IRS: indoor residual spraying 
LLINs: long lasting insecticide-treated nets

WHO: World Health Organization

KDR: knockdown resistance

PCR: Polymerase chain reaction assay

PBO: Piperonyl butoxide

MFOs: mixed-function oxidases

\section{Declarations}

\section{Authors' contributions}

RE, JI and DO conceived, contributed design of the study, field collections, performed laboratory work, analyzed the data, and drafted an initial version of the manuscript. JA, PM, GMM and TI performed laboratory work and analyzed the data. EAO conceived, designed the study, coordinated fieldwork and provided guidance. All authors read and approved the final manuscript.

\section{Author details}

${ }^{1}$ Faculty of Science, Gulu University, P. O. Box 166,Gulu, Uganda,

${ }^{2}$ Gulu University Biosciences Research Laboratories, P. O. Box 166,Gulu, Uganda.

${ }^{3}$ Department of Biochemistry, Biotechnology Research Institute - Kenya Agricultural and Livestock Research Organization, Kikuyu, Kenya

\section{Acknowledgements}

We are grateful to the communities in in Moroto district in Karamoja region for participating in this research.

\section{Competing interests}

The authors declare that they have no competing interests.

\section{Availability of data and materials}

The authors declare that all the main data supporting the findings of this study are available within the article. Any additional data sets are available from the corresponding author upon reasonable request.

\section{Consent for publication}

Not applicable.

\section{Ethics approval and consent to participate}


This study was approved by Gulu University Ethical Review Committee. Formal approval to conduct the study was granted by the Uganda National Council for Science and Technology and the Office of the Ugandan president (SS4610). Community leaders in Moroto district provided written informed consent.

\section{Funding}

The authors disclosed receipt of the following financial support for the research, authorship, and/or publication of this article: This work was supported through the DELTAS Africa Initiative grant \# DEL-15-011 to THRiVE-2 awarded through Career Development Award to Dr. Richard Echodu. The DELTAS Africa Initiative is an independent funding scheme of the African Academy of Sciences (AAS)'s Alliance for Accelerating Excellence in Science in Africa (AESA) and supported by the New Partnership for African's Development Planning and Coordinating Agency (NEPAD Agency) with funding from the Wellcome Trust grant \# 107742/Z/15/Z and the UK government. The views expressed in this publication are those of the author(s) and not necessarily those of AAS, NEPAD Agency, Wellcome Trust or the UK government.

\section{References}

[1] World Health Organization, World Health Statistics 2015, vol. 5, no. 1. 2015.

[2] World Health Organization, WHO / The World malaria report 2018. 2018.

[3] H. Ranson, R. N’Guessan, J. Lines, N. Moiroux, Z. Nkuni, and V. Corbel, “Pyrethroid resistance in African anopheline mosquitoes: What are the implications for malaria control?," Trends Parasitol., vol. 27, no. 2, pp. 9198, 2011.

[4] C. Strode, S. Donegan, P. Garner, A. A. Enayati, and J. Hemingway, "The Impact of Pyrethroid Resistance on the Efficacy of Insecticide-Treated Bed Nets against African Anopheline Mosquitoes: Systematic Review and Meta-Analysis," PLoS Med., vol. 11, no. 3, pp. 1-32, 2014.

[5] WHO, "Conditions for deployment of mosquito nets treated with a pyrethroid and piperonyl butoxide," Glob. Malar. Program. World Heal. Organ., vol. 2017, no. September, pp. 1-5, 2017.

[6] WHO, "The technical basis for coordinated action against insecticide resistance:," World Heal. Organ. Tech. Rep. Ser., no. May, pp. 1-42, 2010.

[7] I. Dusfour et al., "Management of insecticide resistance in the major Aedes vectors of arboviruses: Advances and challenges," PLoS Negl. Trop. Dis., vol. 13, no. 10, pp. 1-22, 2019.

[8] S. G. Staedke et al., "LLIN Evaluation in Uganda Project (LLINEUP) - Impact of long-lasting insecticidal nets with, and without, piperonyl butoxide on malaria indicators in Uganda: study protocol for a clusterrandomised trial," Trials, vol. 20, no. 1, p. 321, 2019.

[9] S. M. \& E. U. Uganda Ministry of Health, National Malaria Control Division, "Annual Report," no. National Malaria Annual Report 2017-2018, pp. 2-72, 2018.

[10] Uganda Bureau of Statistics, "Statistical Abstract Information on: Environmental, Demographic, Socioeconomic, Production and Macroeconomic sectors," Stat. Abstr., no. October, pp. 1-353, 2015. 
[11] U. P. M. I. USAID, “President ' S Malaria Initiative Angola,” USAID, pp. 1-111, 2018.

[12] The Republic of Uganda Ministry of Health, “Uganda Malaria Quarterly Bulletin,” no. 10, pp. 1-11, 2015.

[13] J. Ssempiira et al., "The effect of case management and vector-control interventions on space-time patterns of malaria incidence in Uganda," Malar. J., vol. 17, no. 162, pp. 1-11, 2018.

[14] L. M. Field, T. G. Emyr Davies, A. O. O’Reilly, M. S. Williamson, and B. A. Wallace, "Voltage-gated sodium channels as targets for pyrethroid insecticides," Eur. Biophys. J., vol. 46, no. 7, pp. 675-679, 2017.

[15] N. M. Bowman, K. Akialis, G. Cave, R. Barrera, C. S. Apperson, and S. R. Meshnick, “Pyrethroid insecticides maintain repellent effect on knock-down resistant populations of Aedes aegypti mosquitoes," PLoS One, vol. 13, no. 5, pp. 1-14, 2018.

[16] J. Etang, F. Chandre, P. Guillet, and L. Manga, "Reduced bio-efficacy of permethrin EC impregnated bednets against an Anopheles gambiae strain with oxidase-based pyrethroid tolerance," Malar J, vol. 3, p. 46, 2004.

[17] A. P. Mnzava et al., "Implementation of the global plan for insecticide resistance management in malaria vectors: Progress, challenges and the way forward," Malar. J., vol. 14, no. 173, pp. 1-9, 2015.

[18] J. Hemingway and H. Ranson, “Insecticide Resistance in Insect Vectors of Human Disease," Annu. Rev. Entomol., vol. 45, no. 1, pp. 371-391, 2000.

[19] A. F. Spíndola, C. S. A. Silva-Torres, A. R. S. Rodrigues, and J. B. Torres, "Survival and behavioural responses of the predatory ladybird beetle, Eriopis connexa populations susceptible and resistant to a pyrethroid insecticide," Bull. Entomol. Res., vol. 103, no. 4, pp. 485-494, 2013.

[20] G. Rt, G. Lm, S. Jm, and C. Robin, "Behavioural response to combined insecticide and temperature stress in natural populations of Drosophila melanogaster .," vol. 29, no. 5, p. 26864706, 2016.

[21] C. Nansen, O. Baissac, M. Nansen, K. Powis, and G. Baker, "Behavioral avoidance - will physiological insecticide resistance level of insect strains affect their oviposition and movement responses?," PLoS One, vol. 11, no. 3, pp. 1-12, 2016.

[22] D. G. Lilly, S. L. Latham, C. E. Webb, and S. L. Doggett, "Cuticle thickening in a pyrethroid-resistant strain of the common bed bug, cimex lectularius I. (hemiptera: Cimicidae)," PLoS One, vol. 11, no. 4, pp. 6-16, 2016.

[23] Uganda Bureau of Statistics, "National Population and Housing Census 2014 - Main Report, kampala. Uganda," Uganda Bur. Stat., pp. 1-105, 2016.

[24] World Vision, “Addressing food security and household income challenges," World Vis., p. 2018, 2018.

[25] FAO Forestry Division, "Forests , livelihoods and poverty alleviation : the case of Uganda," FAO, pp. 1-87, 2013.

[26] P. O. Otim, "Baseline Study for the Ugandan side of the Karamoja Cluster," CEWARN/ICAD, Addis Abeba Ethiop., no. May, pp. 1-29, 2004. 
[27] Onor E, “Malaria in Karamoja District, Uganda.” pp. 1-20, 1969.

[28] National Malaria Control Programme, Abt Associates, and the INFORM Project, "An epidemiological profile of malaria and its control in Uganda," no. October, 2013.

[29] UBOS, “Uganda Demograpic and Health Survey 2011,” ICF Int., pp. 1-461, 2012.

[30] M. Gillies and B. DeMeillon, "A Supplement to the Anophelinae of Africa South of the Sahara (Ethiopian zoogeographical region)," South African Inst. Med. Res., no. 55, pp. 1-146, 1987.

[31] WHO/ GMP, "Test procedures for insecticide resistance monitoring in malaria vector mosquitoes: Second edition," World Heal. Organ. Tech. Rep. Ser., pp. 1-54, 2016.

[32] G. E. Ford H.R, "Laboratory rearing of Anopheles albimanus Wiedemann,” Mosq. News, vol. 32, pp. 509$513,1972$.

[33] J. Hemingway, N. J. Hawkes, L. McCarroll, and H. Ranson, "The molecular basis of insecticide resistance in mosquitoes," Insect Biochem. Mol. Biol., vol. 34, no. 7, pp. 653-665, 2004.

[34] H. A. A. Khan, W. Akram, S. A. Shad, and J. J. Lee, "Insecticide Mixtures Could Enhance the Toxicity of Insecticides in a Resistant Dairy Population of Musca domestica L," PLoS One, vol. 8, no. 4, pp. 1-8, 2013.

[35] J. A. Scott, W. G. Brogdon, and F. H. Collins, "Identification of single specimens of the Anopheles gambiae complex by the polymerase chain reaction," Am. J. Trop. Med. Hyg., vol. 49, no. 4, pp. 520-529, 1993.

[36] L. L. Koekemoer, L. Kamau, R. H. Hunt, and M. Coetzee, "A cocktail polymerase chain reaction assay to identify members of the Anopheles funestus (Diptera: Culicidae) group," Am. J. Trop. Med. Hyg., vol. 66, no. 6, pp. 804-811, 2002.

[37] H. Ranson et al., "Identification of a point mutation in the voltage-gated sodium channel gene of Kenyan Anopheles gambiae associated with resistance to DDT and pyrethroids," vol. 9, no. December 1999, pp. 491497, 2000.

[38] Busvine, “Probit Analysis," NCSS Stat. Softw., vol. 575, pp. 1-7, 1971.

[39] S. Horstmann and R. Sonneck, "Contact bioassays with phenoxybenzyl and tetrafluorobenzyl pyrethroids against target- site and metabolic resistant mosquitoes," PLoS One, vol. 11, no. 3, pp. 1-16, 2016.

[40] J. Kitau et al., "Species shifts in the anopheles gambiae complex: Do LLINs successfully control anopheles arabiensis?," PLoS One, vol. 7, no. 3, pp. 1-7, 2012.

[41] R. S. McCann et al., "Reemergence of Anopheles funestus as a vector of Plasmodium falciparum in Western Kenya after long-term implementation of insecticide-treated bed nets," Am. J. Trop. Med. Hyg., vol. 90, no. 4, pp. 597-604, 2014.

[42] F. M. Nafisah Braimah, Chris Drakeley, Eliningaya Kweka, "Tests of bednet traps (Mbita traps) for monitoring mosquito populations and time of biting in Tanzania and possible impact of prolonged insecticide treated net use," Int. Jounral Trop. Insect Sci., vol. 25, no. 3, pp. 208-213, 2007. 
[43] T. L. Russell et al., "Impact of promoting longer-lasting insecticide treatment of bed nets upon malaria transmission in a rural Tanzanian setting with pre-existing high coverage of untreated nets," BMC Malar. J., vol. 9, no. 187, pp. 1-14, 2010.

[44] R. N'Guessan, V. Corbel, M. Akogbéto, and M. Rowland, "Reduced efficacy of insecticide-treated nets and indoor residual spraying for malaria control in pyrethroid resistance area, Benin," Emerg. Infect. Dis., vol. 13, no. 2, pp. 199-206, 2007.

[45] R. Maharaj, "Global trends in insecticide resistance and impact on disease vector control measures," Open access insect physiol., vol. 2011, no. 3, pp. 27-33, 2011.

[46] W. G. Brogdon and J. C. McAllister, "Insecticide resistance and vector control," Emerg. Infect. Dis., vol. 4, no. 4, pp. 605-613, 1998.

[47] M. Okia et al., "Insecticide resistance status of the malaria mosquitoes: Anopheles gambiae and Anopheles funestus in eastern and northern Uganda," BMC Malar. J., vol. 17, no. 157, pp. 1-12, 2018.

[48] M. Okia et al., "Bioefficacy of long-lasting insecticidal nets against pyrethroid-resistant populations of Anopheles gambiae s.s. from different malaria transmission zones in Uganda," Parasites and Vectors, vol. 6, no. 130, pp. 1-10, 2013.

[49] R. John, T. Ephraim, and A. Andrew, "Reduced susceptibility to pyrethroid insecticide treated nets by the malaria vector Anopheles gambiae s.I. in western Uganda," BMC Malar. JournalMalaria J., vol. 7, no. 92, pp. 1-5, 2008.

[50] U. Ramphul, T. Boase, C. Bass, L. M. Okedi, M. J. Donnelly, and P. Müller, "Insecticide resistance and its association with target-site mutations in natural populations of Anopheles gambiae from eastern Uganda," Trans. R. Soc. Trop. Med. Hyg., vol. 103, no. 11, pp. 1121-1126, 2009.

[51] M. Coetzee and L. L. Koekemoer, "Molecular Systematics and Insecticide Resistance in the Major African Malaria Vector Anopheles funestus," Annu. Rev. Entomol., vol. 58, pp. 393-412, 2013.

\section{Additional File}

Additional file 1: KDR Allele frequencies

\section{Figures}




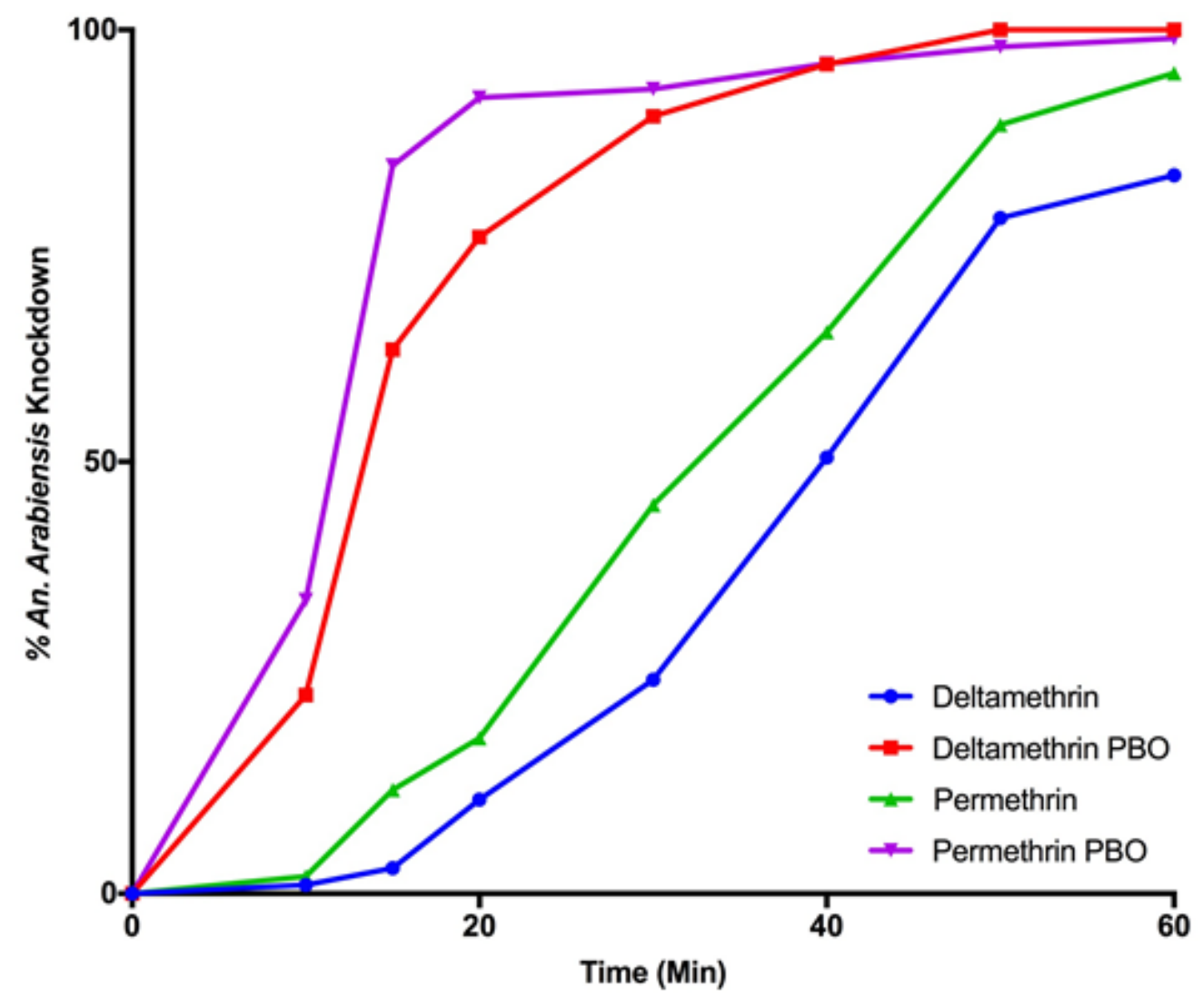

\section{Figure 1}

Percentage of An. arabiensis knocked down during 60-minutes exposure to deltamethrin or permethrin and PBO using WHO tube assay in Moroto District in Uganda, July 2019 (Larval collections)

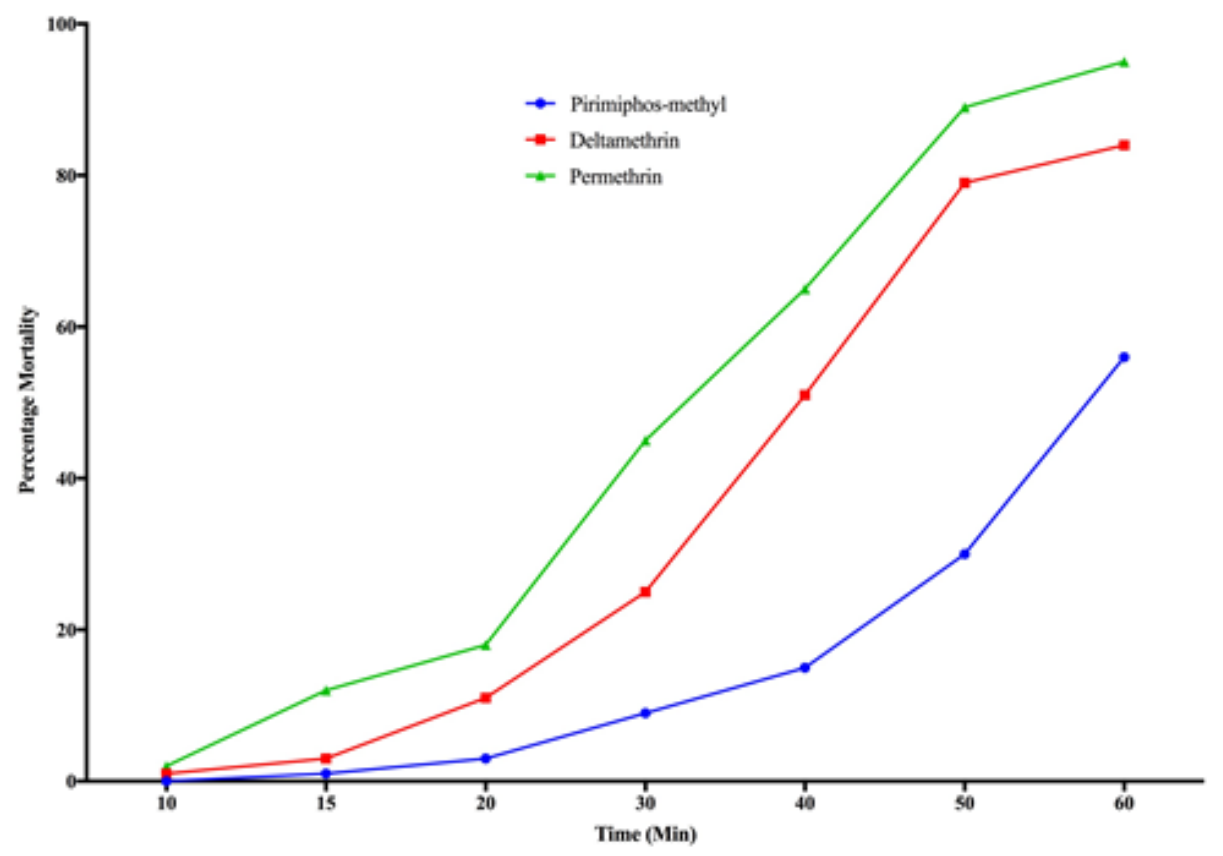


Figure 2

Percentage of An. arabiensis knocked down during 60-minutes exposure to pirirmiphos-methyl, deltamethrin or permethrin using WHO tube assay in Moroto District in Uganda, July 2019 (Larval collections)

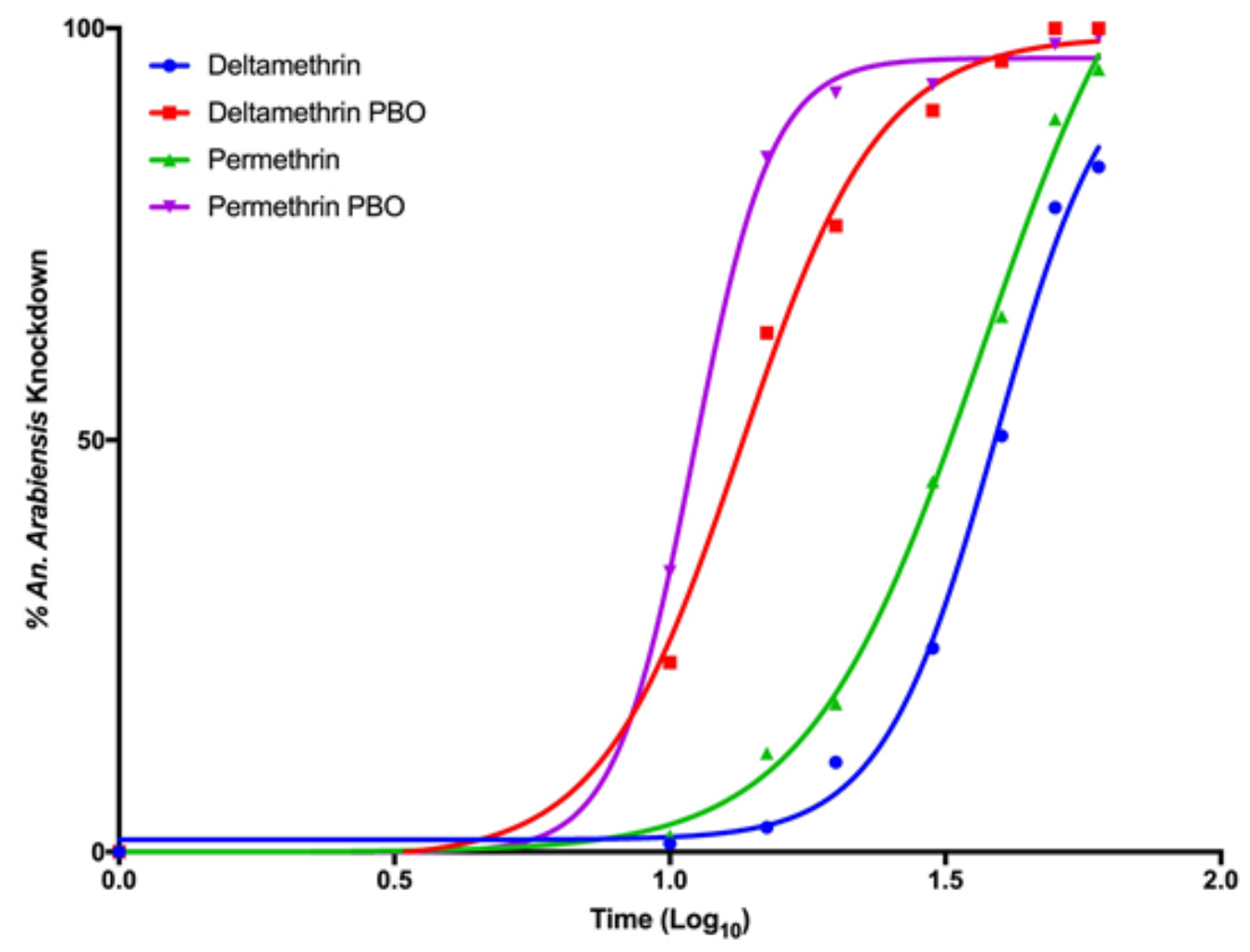

Figure 3

Temporal (log10 minutes) percentage knockdown of Adult female An. arabiensis mosquitoes (from Moroto district, Uganda) by various formulations of pyrethroids.

\section{Supplementary Files}

This is a list of supplementary files associated with this preprint. Click to download.

- Supplementaryappendix1.docx 